\title{
A Comparison Of Team Performances Using Four Scenarios Of Feedback
}

Charles Mohundro, Texas A\&M University-Texarkana, USA

Charles McDonald, Jr., Texas A\&M University-Texarkana, USA

David Reavis, Texas A\&M University-Texarkana, USA

\begin{abstract}
When providing feedback to students working in groups, professors may use a variety of methods. Using computer generated feedback to give direction and correction for group assignments provides a way to maximize the professor's time and provide consistent feedback across different groups and assignments. This article discusses the effect of two types of computer-generated feedback. The first is a semi-automated process for inserting pre-defined comments in student papers (the software is titled Strategy Assistant). This software allows the professor to define the most commonly used feedback information, then easily insert his comments on student papers. The second type is an automated process for giving grammar and style feedback. The automated grammar software (Edit Assist) checks the student paper for numerous grammar and style errors, then automatically inserts comments that identify problems. This article discusses the improvements in group performance with each of these types of feedback and measures the change in student performance during the course of a semester. Both types of feedback tended to improve student performance over the course of the semester, with the Strategy Assistant having the biggest impact on student grades and Edit Assist having the biggest impact on writing style error improvement.
\end{abstract}

Keywords: Automated Feedback, Team, Group, Automated Grading

\section{INTRODUCTION}

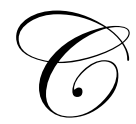

hrist and Christ (2006), in reflecting on the numerous studies in the literature concerning automated feedback and its effect on student behavior and performance, explained that, “...the exploration and applications of technology have not kept pace with the improvements in the availability, flexibility, and reduced costs of technology." The increasing demand for analytical Web-delivered courses and the evaluation of student's efforts is forcing professors to seek technology solutions to help manage the development and delivery of these courses. In addition, it is explained that there is a perceived greater work requirement for developing and teaching a Web-based course versus the same class in a traditional format (Shea, 2007). The Web-based Managerial Policy \& Strategy course was utilized for this study. It is a graduate capstone course requiring the application and integration of principles from various business disciplines, including accounting, finance, marketing, management, and economics in the solution of managerial problems and the development and implementation of corporate strategies in a changing environment. The time demands of this course bolstered a need for technology to increase the professor's efficiency in time management and teaching effectiveness to foster increased student learning.

This research explores the effect of semi-automated feedback (use of an application that inserts predeveloped comments via a mouse-click) on student performance in the application of crafting and executing business strategy principles (identification and analysis of the firm's external and internal environment, past and present strategy identification, formulation of problem solutions and action plans, identification and valuation of alternative strategies, and formulation and support of recommended strategy). This research also focuses on the effectiveness of automated feedback in improving students' writing, organizational, and presentation skills in reporting their analysis, findings, and recommendations. 
Specifically, this study will focus on analyzing team performance based on case scores where four scenarios of feedback were provided. The effect of semi-automated computer generated feedback concerning content will be explored by analyzing the number of professor's comments related to content versus the case grade. The effect of automated editing feedback concerning writing performance will be explored by analyzing the number of grammar and style errors identified in the analyses versus the case grade.

\section{REVIEW OF THE LITERATURE}

Some of the earliest research conducted to evaluate automated feedback in an educational environment used devices such as timers, whistles, buzzers, and lights to provide feedback to groups of students. In one study, feedback signaled the group when the noise level reached a certain point, so students could know where the threshold was between acceptable noise levels and unacceptable noise levels. Once the noise level reached a threshold, an automated feedback device, such as a buzzer, would sound to signal the students that they needed to reduce the noise level (Schmidt and Ulrich, 1969). Other studies observed how automated feedback can affect student behavior and performance, but Christ and Christ (2006) explain that, “...the exploration and applications of technology have not kept pace with the improvements in the availability, flexibility, and reduced costs of technology."

Evaluating team performance encompasses numerous performance components. Various studies conducted in recent years proposed methods for defining and analyzing these components to understand how teams function and how teams achieve success. Fleishman and Zaccaro (1992) developed a widely referenced taxonomy to classify team functions, which includes orientation functions, motivational functions, systems monitoring functions, and adjustments of nonstandard activities. Militello (1999 or 2000) proposed a model of team performance, based on six previously defined models, that synthesizes components from the earlier models into one cohesive model. Militello's model includes provisions for monitoring and adjusting team performance, as do all of the previously defined models. The "monitor and adjust" process is part of the team's self-management function but the details of how the team receives and processes feedback is not addressed in the model proposal.

One common method for analyzing the learning process in a computer-supported collaborative learning (CSCL) environment is to assess individual learning processes through an evaluation of student performance. Since CSCL environments tend to produce electronic data for objective evaluation, it is necessary to consider the differences in the data that might be available from a CSCL platform. Raw data may include computer-generated log files, tracking data such as mouse clicks or pages visited, or time spent viewing specific assignments or course content Web pages. Additional data describes the learning format and may include characteristics of the student group(s), course design, or course components. Subjective data may include student beliefs, attitudes, or opinions concerning the course (Pozzi et al, 2007).

Pozzi (2007) suggests that both qualitative and quantitative analyses are important in evaluating a CSCL based learning process. The framework he proposes is based on Henri's (1992) and Garrison and Anderson's (2003) models and consist of participative, interactive, social, cognitive and meta-cognitive, and teaching dimensions. Garrison, Anderson, and Archer (2001) define cognitive presence as "the extent to which learners are able to construct and confirm meaning through sustained reflection and discourse in a critical community of inquiry." Pozzi describes problem recognition, exploration, integration of ideas and feedback, and resolution as the four thematic units of the cognitive dimension. Pozzi confirms that further research is needed to detect and measure the metacognitive skills that may be developed through a CSCL, but does not develop methodology for analysis of various types of feedback that affect the cognitive and meta-cognitive dimension of the learning process.

Building on the work of previous researchers, Rico and Cohen (2005) conducted experiments to assess the effects of task interdependence and different methods of communication in virtual teams. They conclude that team members performing tasks with a high level of interdependence, such as the student assignments in this study, may perform at a higher level when there is a higher level of synchrony in the communication channel. Numerous researchers suggest that the interaction between the communications technologies and the kind of task performed needs further analysis (Bell \& Kozlowski, 2002; Maznewski \& Chudoba, 2000; Maznewski \& Atanassiou, 2003; Montoya-Weiss et al., 2001). 


\section{RESEARCH METHODOLOGY}

Students in four sections of the MBA capstone course (Managerial Policy \& Strategy) at Texas A\&M University-Texarkana offered via a Web-based format were involved in the study. The course required students to apply and integrate principles from various business disciplines including accounting, finance, marketing, management, and economics in the identification and solution of managerial problems and the development and implementation of corporate strategies in a changing environment. The course was taken during the students' last semester and required that students had completed all MBA background courses or if a student was pursuing MSBA degree, students had completed all required leveling courses.

Students self-selected their course section at registration. In an effort to simulate the normal work environment that most students will be a part of, teams were employed in reaching the teaching objectives. Students in each of the four sections self-selected their four or five member teams as well. A student not self-selecting a team was randomly placed on a team. This resulted in four teams in three course sections and five teams in one section totaling 81 students involved in the study. Each of the four class sections were randomly assigned feedback as follows:

- In section 1, teams would only receive a score on their case analyses with no additional feedback.

- In section 2, teams would receive a score and computer-generated comments concerning grammar and style errors. The Edit Assist program was used to accomplish this and is described in the Test Instruments section below.

- In section 3, teams would receive a score and semi-automated professor's comments only. The professor's semi-automated comments program is described in the Test Instruments section below and hereinafter is referred to as Strategy Assistant.

- In section 4, teams would receive both computer-generated comments from Edit Assist and the professor's comments using Strategy Assistant.

For this study, three relatively complex cases were used for the team assignments:

- Near the beginning of the course, the "Dell Inc. in 2006: Can Rivals Beat Its Strategy?" case was assigned.

- $\quad$ Near mid-semester, the "Adidas: Will Restructuring Its Business Lineup Allow It to Catch Nike" case was assigned.

- Near the end of the semester, the "eBay: Facing the Challenge of Global Growth" case was assigned. (Thompson, 2007).

Student analysis and report write-ups for cases at this level of complexity normally consist of 20 to 30 pages depending on writing style, succinctness, and depth of coverage. In order to assure fairness among all sections and to eliminate concerns of the test subjects relating to grade advantage or disadvantage by participating in the study, all teams were assured that grades would not be affected by this study and that should there be any sectional grade advantage because of the study, proper equity or leveling adjustments to their case scores would be made.

\section{Test Instruments}

The test instruments, in addition to the cases mentioned above, consisted of two computer programs: an automatic grammar and style analysis program and a semi-automatic program with standardized comments developed by the professor for the course. Both programs were used in these classes to increase time efficiency, consistency of feedback, and teaching effectiveness.

\section{Strategy Assistant}

The comments used in Strategy Assistant were developed by the professor and refined over several years to provide meaningful feedback when evaluating cases in the Managerial Policy \& Strategy course. Prior to the start of the semester, Strategy Assistant was developed to automate the decimation of these comments. 
Strategy Assistant is a computer program that runs in Microsoft Word and permits the professor, while scoring an analysis prepared in Word, to insert comments by blocking a deficient section or subsection and clicking 1 of 19 menu choices (see Table 1) to insert a pre-prepared comment at the beginning of the students' analysis. The professor's comments outline the content that should be in the student's analysis. Figure 1 depicts portions of a team's paper and the Strategy Assistant menu.

Figure 1: Strategy Assist Menu and Student Paper

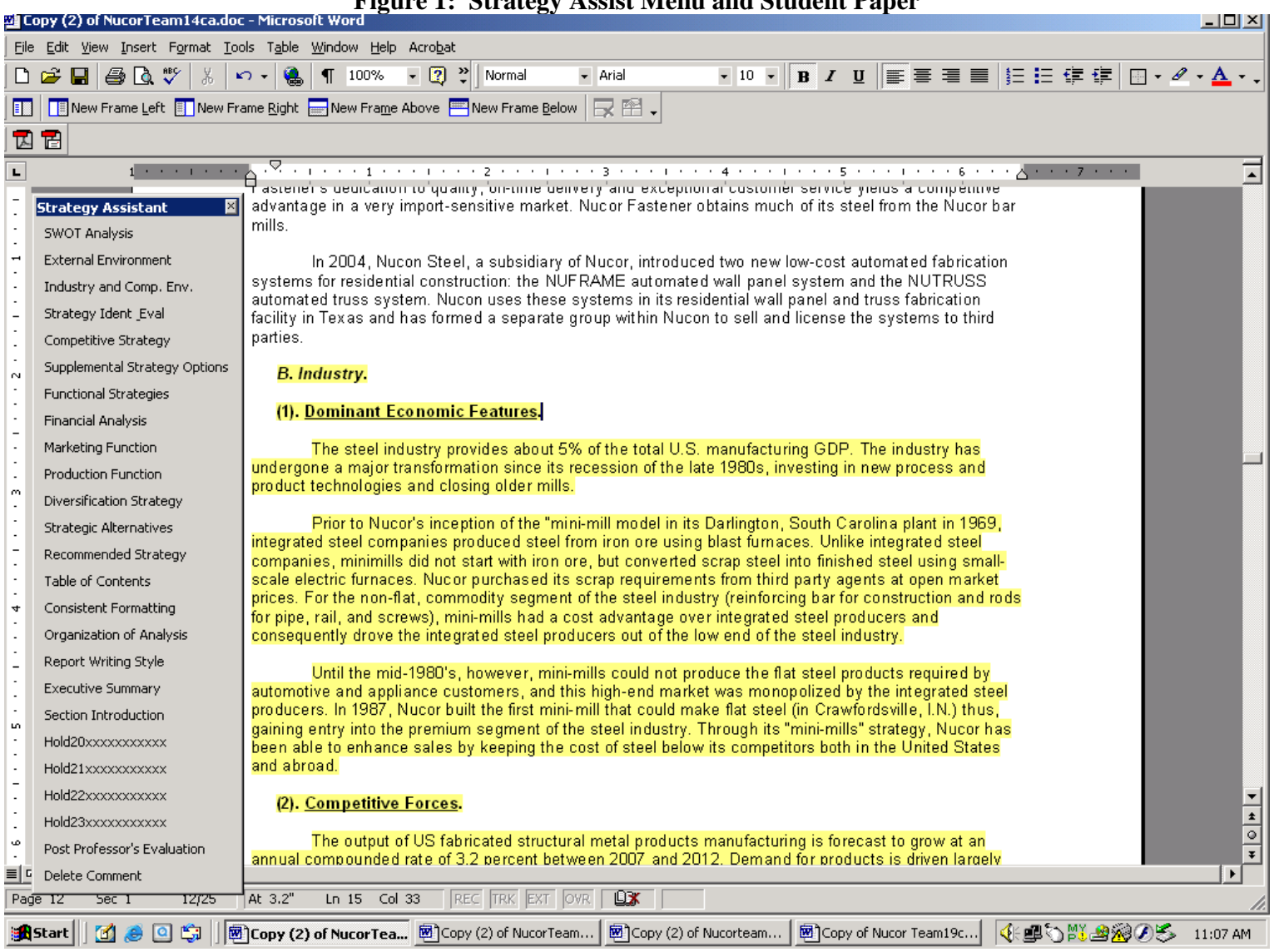

Table 1: Strategy Assistant's Menu used in this Study Offers 19 Menu Choices

\begin{tabular}{|l|l|l|}
\hline \multicolumn{1}{|c|}{ SWOT Analysis } & \multicolumn{1}{|c|}{ Financial Analysis } & \multicolumn{1}{c|}{ Organization of Analysis } \\
\hline External Environment & Marketing Function & Report Writing Style \\
\hline Industry and Competitive Environment & Production Function & Executive Summary \\
\hline Strategy Identification \& Evaluation & Diversification Strategy & Section introduction \\
\hline Competitive Strategy & Strategic Alternatives & Post Professor's Evaluation \\
\hline Supplemental Strategy Options & Recommend Strategy & Delete comments \\
\hline Functional Strategies & Table of contents & \\
\hline Financial Strategies & Consistent Formatting & \\
\hline
\end{tabular}

The professor's comments vary in length and range from a short paragraph addressing the "Table of Contents" to several paragraphs including bullets to address the "Industry and Competitive Environment" section. All comments made by the professor appear at the beginning of the analysis (see Figure 2). 
Figure 2: Professor Evaluation Posting at Beginning of Student Analysis

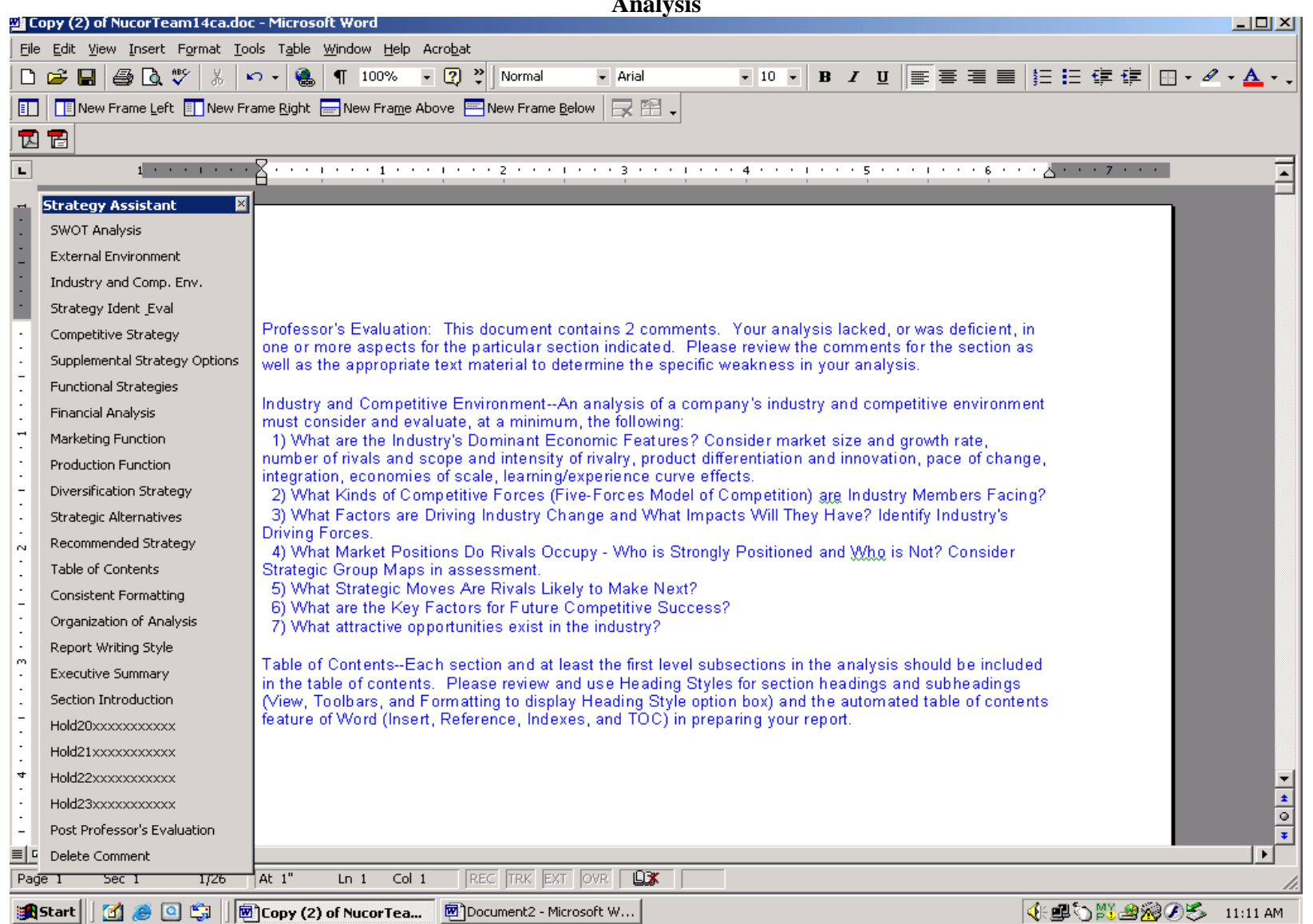

\section{Edit Assist}

The Edit Assist software was developed over a three-year period to assist professors in evaluating electronically submitted papers by reducing the drudgery of commenting rudimentary errors. With a mouse-click, this tool automatically scans documents, detects areas of concern, and inserts comments to identify grammar or writing style problems. In this study, the Edit Assist tool applied over 200 grammar and style rules that addressed:

- $\quad$ clichés, colloquial expressions, and conversational writing

- $\quad$ one-sentence paragraphs

- $\quad$ words that are inappropriate, repeated, or not listed in a dictionary

- use of first or second person

- $\quad$ use of nonstandard expressions

- $\quad$ misuse of conjunctive adverbs

- $\quad$ long sentences

- $\quad$ miscellaneous grammar and style errors

\section{Scoring And Feedback Procedure}

Teams were informed of the scoring procedure to be used in evaluating their analyses at the beginning of the semester and again prior to the submission of their first case analysis as follows: 
The case analyses are graded holistically. This means that the professor reviews the completeness of the analysis coverage, the content of the various areas of analysis, the clarity of the writing and organization, the logic and rationale and how well the team supports a position on strategy alternatives and recommendations (even thought the professor might not agree with the team's recommendations) and evaluate the entire report on the basis of "A+" (97-100), “A” (94-96), “A-“(91-93), “A-“"(89-90), "B" (88-85), etc.

The scoring and feedback procedure consisted of the following:

- $\quad$ The same professor scored each of the three case analyses and was kept purposefully unaware of any team's section assignment and any research data until after all three cases had been scored.

- $\quad$ Each of the professor's reviews included:

- Standardized comments using Strategy Assistant

- Comments that identified grammar or style errors using Edit Assist.

- $\quad$ Section 1 papers were returned to the teams with the Strategy Assistant and Edit Assist comments removed. These papers contained only the team's score.

- $\quad$ Section 2 papers were returned to the teams with the Strategy Assistant comments removed. These papers contained the team score and comments from Edit Assist.

- $\quad$ Section 3 papers were returned to the teams with the Edit Assist comments removed. These papers contained the team score and comments from Strategy Assistant.

- $\quad$ Section 4 papers were returned to the teams with the team score, the comments from Strategy Assistant, and comments from Edit Assist.

\section{Data Analysis}

The research question addressed by the study can be expressed as:

"What is the effect, if any, of automated and/or semi-automated computer generated feedback on students (teams) learning in a highly analytical and synthesizing environment?"

To address the question, the investigators used two computer programs developed for their class use, Edit Assist, an extensive document analyzer for grammar and style, and Strategy Assistant, a semi-automatic content feedback program, in a multi-section graduate MBA capstone course. The sections included a control section, a section exploring the effect of Edit Assist's feedback, a section addressing the effect of Strategy Assistant's feedback, and a section investigating the combined effect of feedback from both programs. A major focus of the research was to analyze team performance based on changes in case scores using four scenarios of feedback. The number of editing comments did not relate directly to average team scores except in the overall impression of the quality of the paper.

In section 1, the control group, students received only a grade for feedback. The data reflects that there was insignificant change in the grade performance of section 1 teams across the semester. The average number of Strategy Assistant comments increased slightly from 3.75 on case 1 to 4.5 on case 3 . Although grade averages increased only .5\%, there was a significant increase of $66.9 \%$ in the number of grammar and writing style errors detected by Edit Assist. As a major part of the case evaluation was based on content, it appears that, without feedback, little concern for grammar and writing style was expended. See figure 3 and figure 7. 
Figure 3: Section 1 - Received Team Score Only Feedback

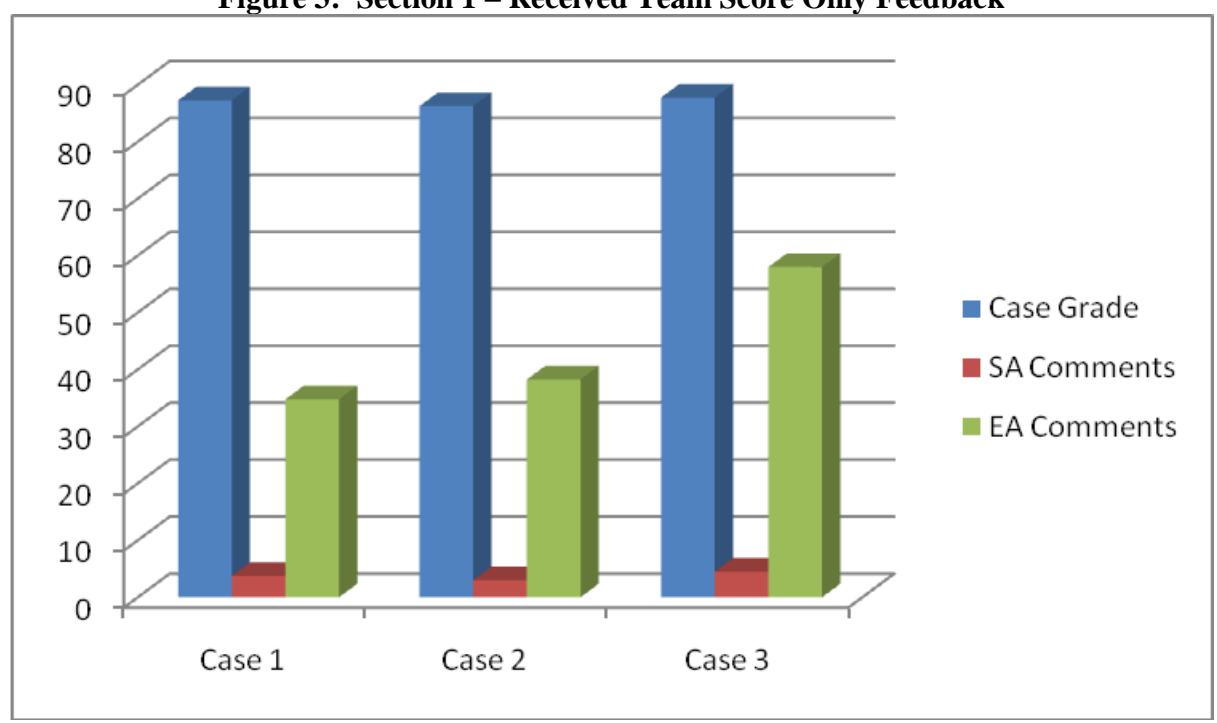

In section 2, students received feedback containing the team score and comments generated from Edit Assist. Although the writing quality improved on each case, the value of content declined. It appears that feedback from Edit Assist reduced the number of grammar and writing style comments by about $40 \%$ across the three cases. This section's average score remained a consistent 93.75 for the first two cases, but on case3, their average score dropped to 88.75; thus, this section saw a grade average decrease of 5.3\%. As all other sections achieved their highest grade on case3, it appears that this section concentrated on reducing grammar and style errors and limited their effort in addressing this case's content. These students may have perceived that with comments addressing only grammar and writing style, their efforts should focus on these areas (see Figures 4 and 7).

Figure 4: Section 2-Received Team Score and Edit Assist Feedback

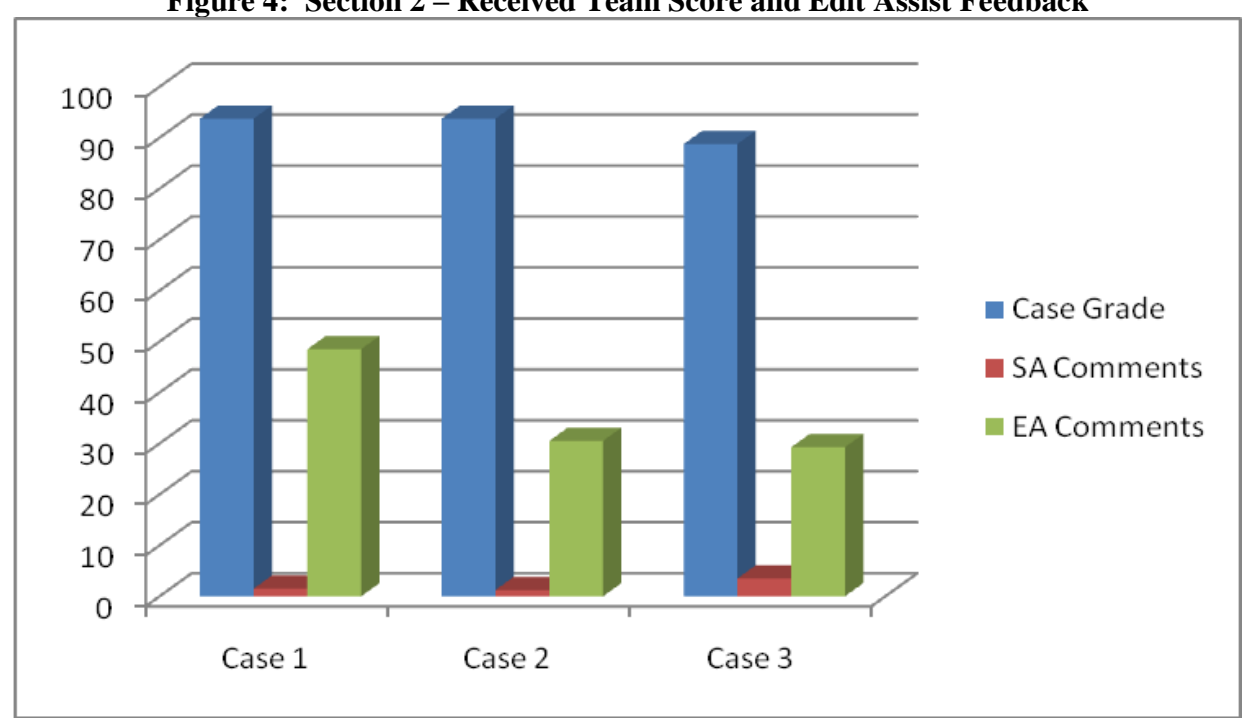

In section 3, students received feedback containing the team score and the professor's comments using Strategy Assistant. As grades were largely based on content and the professor's comments addressed content issues, it was not unexpected that grade averages rose 5.2\%. Comments on case1 averaged 2.4 per team; whereas, comments averaged only 1.2 on case 2 and case 3 . In addition, without feedback related to grammar and writing style, the number of errors rose from an average of 36 on case 1 to 47.75 on case 3 . See figure 5 and figure 7. 
Figure 5: Section 3 - Received Team Score and Strategy Assistant Comments

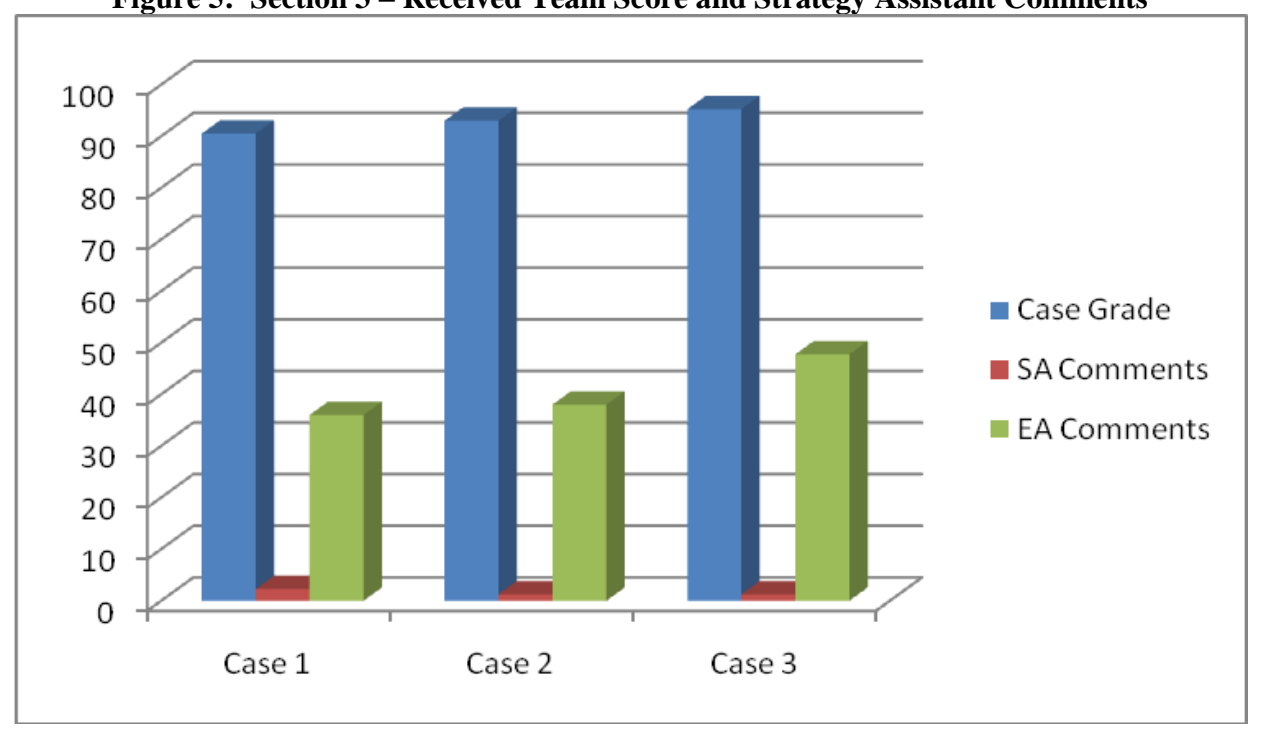

In section 4, students received feedback containing the team score, the professor's comments using Strategy Assistant, and comments generated from Edit Assist. This section increased their average grade by 3.6\%. The average number of professor's comments decreased from 5.5 on case 1 to 3.5 on case 3 , but the number of comments generated from Edit Assist averaged about 36 on all three cases. As grammar is not emphasized in holistic grading, students in this section, apparently, focused on comments from Strategy Assistant to address content in succeeding cases (see Figures 6 and 7).

Figure 6: Section 4 - Team Score, Strategy Assistant and Edit Assist Comments

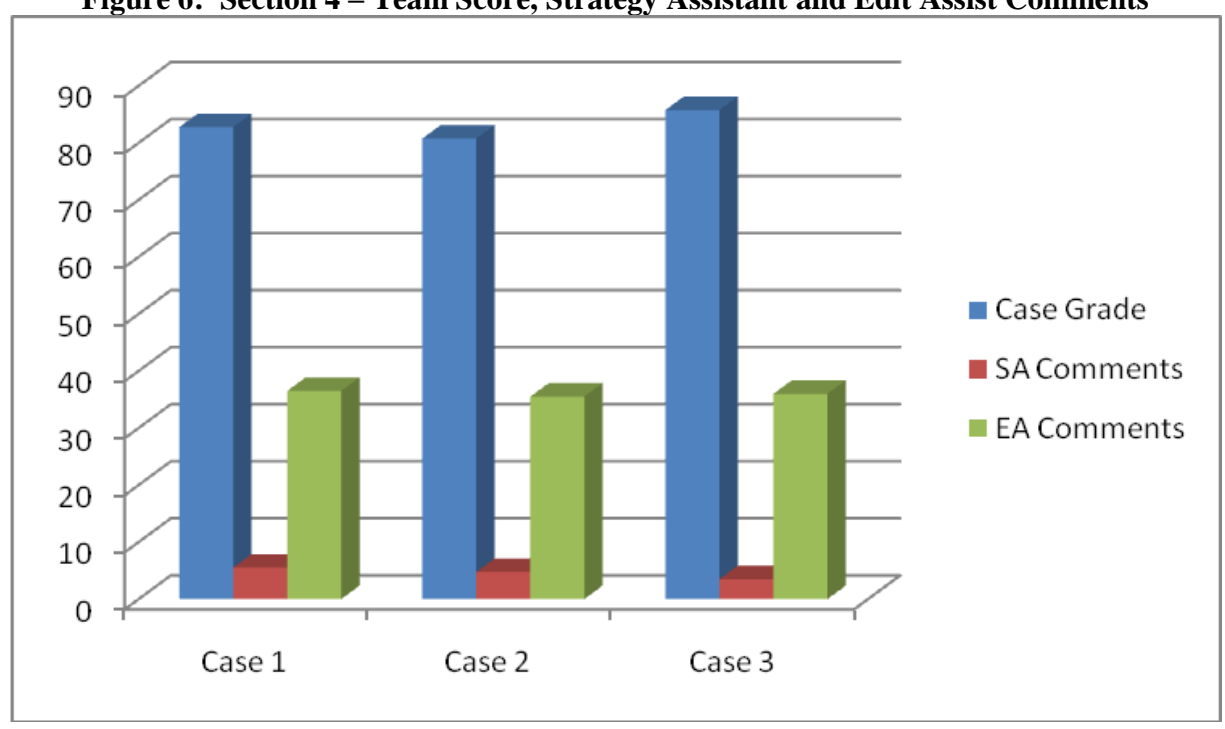


Figure 7: Percentage of Change in Team Grades by Section and Case

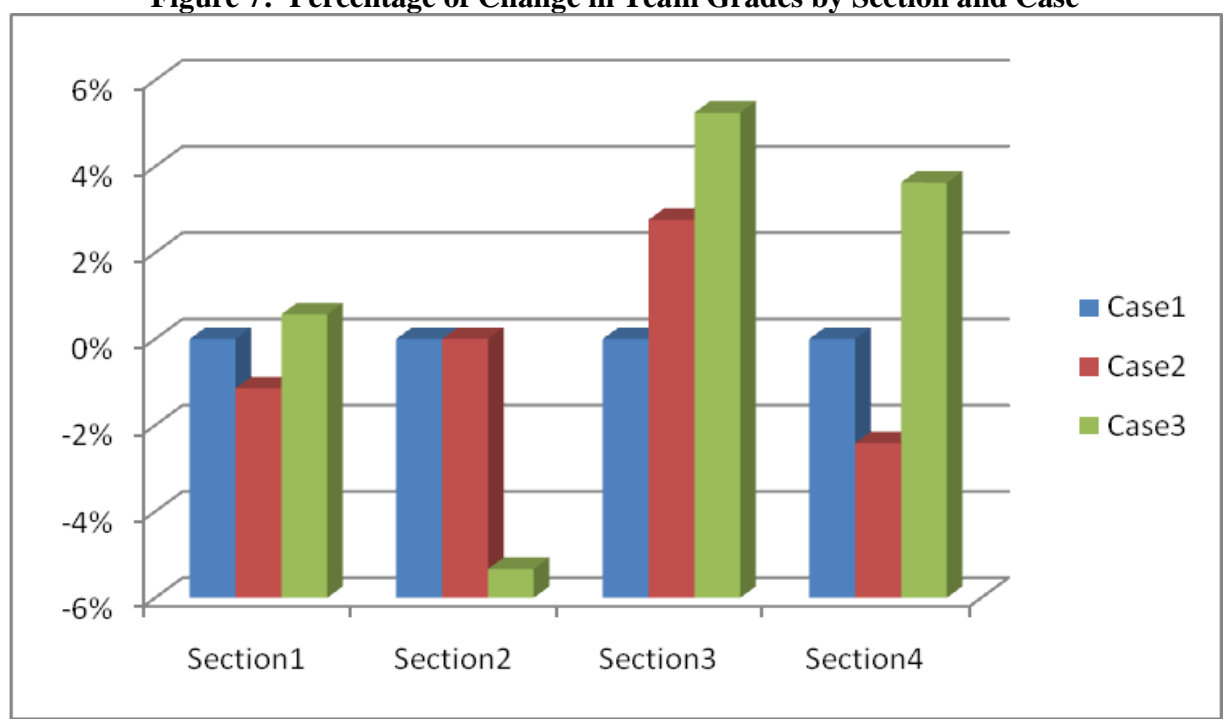

\section{CONCLUSIONS}

The data generated by the study did support an answer to the research question posed:

"What is the effect, if any, of automated and/or semi-automated computer generated feedback on student (team) learning in a highly analytical and synthesizing environment?"

\section{Content Feedback}

The data indicates that semi-automated computer generated feedback using Strategy Assistant did increase team performance. Team case grades increased an average of 5.2\% across the semester. As grades are biased to reflect content versus grammar, this was expected.

\section{Grammar and Style Feedback}

The data relating to teams receiving only computer-generated grammar and style feedback (plus a grade) indicates that team performance concerning grades declined by $5.3 \%$; although, grammar and writing style errors were reduced by $40 \%$. As grammar is not emphasized in holistic grading and feedback concerning content was not provided, this performance was not unexpected. It was interesting to note that in each section, the case receiving the lowest grade also contained the highest number of comments from Edit Assist.

\section{Content Feedback plus Grammar and Style Feedback}

Teams receiving a grade, comments from Strategy Assistant, and comments from Edit Assist increased their average grade by 3.6\%. The first case returned an average of 5.5 comments from Strategy Assistant, but by the third case, these comments were reduced to an average of 3.5. The comments from Edit Assist remained consistent at about 36 for each case.

\section{Areas for Further Study}

Further research into the relevant effectiveness of the more traditional professor's interlinear notes, which by necessity are relatively cryptic, and the more detailed feedback possible via automated methods would likely provide additional insight to professor's in their quest to create the best possible leaning environment for their students. Also, research into the effectiveness of the extent and level of detail of automated feedback should receive further study. 


\section{AUTHOR INFORMATION}

Charles Mohundro has been involved in various aspects of distance education for almost half of his 40 year teaching career. During the early and middle portions of his career, Mohundro was also involved in the ownership of several small businesses as well as in business and legal consulting primarily with small businesses in the general areas of business initiation and early growth. Prior to becoming a university professor, Mohundro served as VicePresident and General Counsel for a private holding company engaged in the sale, rental, leasing and parking of automobiles, general construction, insurance and real estate ownership and management.

Charles McDonald is a Professor of Management Information Systems at Texas A\&M University-Texarkana where he has served as a faculty member for over 20 years. His background includes software development, electronic hardware design, systems analysis, process control systems, and database theory. His latest software project is ScanMyDocument.com, which provides a service to scan and comment documents by applying over 600 grammar and style rules. He enjoys woodworking, fishing, gardening, and baking.

David Reavis teaches both Web-based and traditionally formatted classes in management information systems at Texas A\&M University-Texarkana. His work experience includes software development roles for manufacturing companies such as Cooper Tire and Rubber Co. and Alcoa. Reavis received his undergraduate BBA in computer information systems from Southern Arkansas University, his MBA from Texas A\&M University-Texarkana and his $\mathrm{PhD}$ in information systems from Nova Southeastern University.

\section{REFERENCES}

1. Bell, B. \& Kozlowski, S. (2002). A typology of virtual teams: Implications for effective leadership. Group and Organizational Management. 27(1), 14-49.

2. Christ, J. \& Christ, T. (2006). An application of an interdependent group contingency mediated by an automated feedback device: An intervention across three high school classrooms. School Psychology Review, 35(1), 78-90.

3. Fleishman, E., \& Zaccaro, S. (1992). Toward a taxonomy of team performance functions. In R. W. Swezey $\&$ E. Salas (Eds.), Teams: Their training and performance (pp. 31-56). Norwood, NJ: Ablex.

4. Garrison, R., Anderson, T. \& Archer, W. (2001). Critical thinking, cognitive presence, and computer conferencing in distance education. American Journal of Distance Education, 15(1), 3-21.

5. Garrison, R, \& Anderson, T (2003). E-learning in the 21 st century. A framework for research and practice. London and New York: RoutledgeFalmer.

6. Henri, F. (1992). Computer conferencing and content analysis. In A. Kaye (Ed.) Collaborative learning through computer conferencing: The Najaden papers (pp. 115-136). New York: Springer.

7. Maznewski, M. \& Atanassiou, N. (2003). Designing the knowledge-management infrastructure for virtual teams: building and using social networks and social capital. In Gibson, C. \& Cohen, S. (Eds.) Virtual teams that work: Creating conditions for virtual team effectiveness (pp.196-213). New York: John Wiley \& Sons.

8. Maznewski, M. \& Chudoba, K. (2000). Bridging space over time: Global virtual team dynameics and effectiveness. Organization Science. 11(5), 473-492.

9. Militello, L, Kyne, M, Klein, G, Getchell, K, \& Thordsen, M (1999). A synthesized model of team performance. International Journal of Cognitive Ergonomics. 3(2), 131-158.

10. Montoya-Weiss, M., Massey, A., \& Song, M. (2001). Getting it together: Temporal coordination and conflict management in global virtual teams. Academy of Management Journal. 44(6), 1251-1262.

11. Pozzi, F, Manca, S, Persico, D, \& Sarti, L (2007). A general framework for tracking and analyzing learning processes in computer-supported collaborative learning environments. Innovations in Education and Teaching International, 44(2), 169-179.

12. Schmidt, G. \& Ulrich, R. (1969). Effects of group contingent events upon classroom noise. Journal of Applied Behavior Analysis, 2, 171-179.

13. Shea, P, (2007) Bridges and barriers to teaching online college courses: a study of experienced online faculty in thirty-six colleges. Journal of Asynchronous Learning Networks, 11(2), 73.

14. Thompson, Arthur A., Jr., A. J. Strickland III, and John E. Gamble 2007, "Crafting and Executing Strategy: The Quest For Competitive Advantage: Concepts and Cases" 15th ed. New York: McGraw-Hill Irwin. 